IFAS Extension

\title{
Trastornos fisiológicos de la papa - Centro marrón y Corazón hueco ${ }^{1}$
}

\author{
L. Zotarelli, C. Hutchinson, S. Byrd, D. Gergela, y D. L. Rowland ${ }^{2}$
}

El centro marrón y el corazón hueco son trastornos fisiológicos internos no-infecciosos del tubérculo de la papa. Un centro marrón (también llamado corazón incipiente y hueco, corazón marrón o centro de azúcar) se caracteriza por una región muerta en las células de la médula de los tubérculos lo que resulta en un tejido de color marrón. El corazón hueco se caracteriza por una depresión en forma de estrella o en forma de lente en el centro del tubérculo (Figura 1) (Hiller, Koller yThornton1985). Aunque el centro marrón con frecuencia precede el desarrollo del corazón hueco, ambos trastornos suelen ocurrir por separado. El corazón hueco puede ocurrir sin ser precedido por el centro marrón (Hiller y Thornton 2008). La probabilidad de incidencia de un centro marrón que resulte en un corazón hueco se basa en la tasa de crecimiento del tubérculo después de un período de estrés (Hiller, Koller, y Thornton1985). Cuanto más grande sea el tubérculo y crezca más rápido, la susceptibilidad es mayor a que el tubérculo tenga incidencia de corazón hueco (Hiller, Koller, y Thornton 1985). Ninguno de los trastornos es iniciado por un agente transmisor de enfermedad.

Un corazón hueco y un centro marrón impactan negativamente la calidad del tubérculo. El trastorno hace los tubérculos para mercado fresco poco atractivos y puede reducir las ventas. El corazón hueco puede impactar negativamente la calidad del procesamiento de las papas

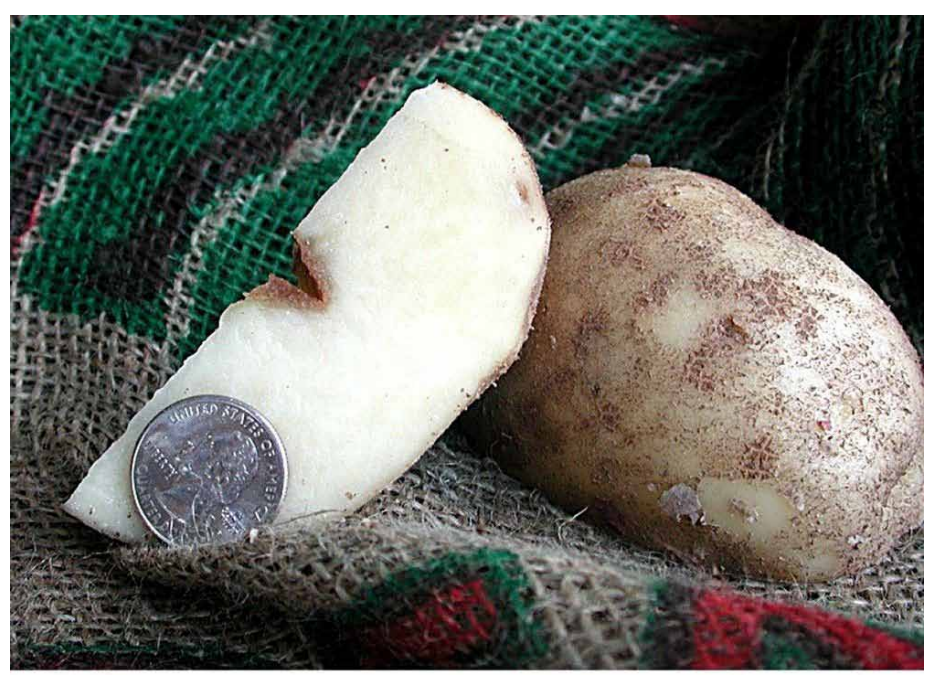

Figure 1. Corazón hueco en 'Atlantic'

Credits: C. Hutchinson

fritas y puede resultar en cargamentos que no cumplen los estándares de calidad requeridos. Sin embargo, ningún desorden es reportado como dañino y ninguno afecta el sabor del tubérculo ni la nutrición.

Un centro marrón y un corazón hueco aparecen en mayor incidencia cuando las condiciones de crecimiento cambian abruptamente durante la temporada de cultivo, tal es el caso cuando las plantas de papa se recuperan demasiado rápido después de un período de estrés ambiental y/o nutricional. Cuando los tubérculos comienzan a crecer rápidamente, la

1. Este documento, HS1214, es uno de una serie de publicaciones del Horticultural Sciences, Servicio de Extensión Cooperativa de la Florida, Instituto de Alimentos y Ciencias Agrícolas, Universidad de la Florida. (UF/IFAS). Fecha de primera publicación: enero 2013. Visite nuestro sitio web EDIS en <http:// edis.ifas.ufl.edu>. This is a translation of HS945, Potato Physiological Disorders - Brown Center and Hollow Heart.

2. L. Zotarelli, assistant professor, Horticultural Sciences Department; C. Hutchinson, former associate professor, Horticultural Sciences Department; S. Byrd, graduate student, Agronomy Department; D. Gergela, research coordinator, Florida Partnership for Water, Agriculture and Community Sustainability at Hastings; and D. L. Rowland, associate professor, Agronomy Department, Cooperative Extension Service, Institute of Food and Agricultural Sciences, University of Florida, Gainesville, FL 32611. 
médula del tubérculo puede morir o separarse, dejando un espacio vacío en el centro. Los efectos del centro marrón y el corazón hueco probablemente se forman durante el inicio del tubérculo pero también se pueden formar durante el llenado del tubérculo (Christ 1998). Si el trastorno se produce durante la primera parte de la temporada, entonces ésta es precedida más a menudo por un centro marrón que se forma en la parte terminal del pedúnculo del tubérculo, mientras que la formación tardía del corazón hueco ocurre usualmente cerca del final del brote sin que ocurran los síntomas del centro marrón (Christ 1998).

El daño a las células que dan señalización a la aparición del centro marrón puede ocurrir bajo condiciones tales como temperaturas del suelo inferiores a $56 \mathrm{~F}$ por 5 a 8 días consecutivos, o cuando la humedad del suelo es mayor de 80\% (Bussan 2008; Christ 1998; Van Denburgh, Hiller, y Koller 1986). La incidencia del centro marrón y del corazón hueco también aumenta con períodos de estrés debido a altos o bajos niveles de humedad (Selman et al. 2008), especialmente si la aplicación de agua es seguida por un período de estrés debido a los bajos niveles de humedad (Christ 1998). Debido que los tubérculos grandes son más propensos a desarrollar este trastorno, y un amplio espaciamiento entre plantas produce tubérculos más grades, lo que a su vez resulta en una mayor incidencia del centro marrón y corazón hueco (Christ 1998).

Existen diferencias en la susceptibilidad de las variedades de la papa en cuanto al corazón hueco y el centro marrón. La variedad 'Atlantico' es la más cultivada en Florida para la elaboración de papas fritas y es relativamente susceptible a ambos trastornos. En la variedad 'Atlantico', el corazón hueco es visto amenudo conjuntamente con una necrosis de calor interno debido a que ambos trastorno están relacionados con el estrés. En 'Russet Burbank', la susceptibilidad a ambos trastornos de centro marrón y corazón hueco es mucho mayor poco después de la iniciación cuando los tubérculos son pequeños (McCann y Stark 1989). Los resultados de los ensayos en la variedad de papas de Florida indican una incidencia muy baja de centro marrón en el Noreste de Florida en la mayoría de las papas cultivadas con subirrigación.

Las decisiones y las prácticas culturales de los productores pueden ser usadas para reducir la incidencia de estos trastornos. La selección de variedades que son conocidas por ser menos susceptibles y el retrasar la siembra hasta que la temperatura del suelo alcance los niveles adecuados pueden disminuir la ocurrencia del centro marrón y el corazón hueco (Christ 1998). El sembrar con una semillas más grande y de menor edad pueden también reducir el riesgo de centro marrón y de corazón hueco debido al aumento del número de tallos por unidad de semilla (Hiller y Thornton 2008; Rex y Mazza 1989). Alcanzando el soporte recomendado, evitando espacios en la siembra y aplicando múltiples y pequeñas, $\mathrm{o}$ aplicaciones fraccionadas de fertilizantes (especialmente nitrógeno) son prácticas que pueden reducir la incidencia del centro marrón y el corazón hueco (Hiller y Thornton 2008). El mantenimiento de una humedad constante en el suelo mediante la aplicación de riego uniforme es crítico para evitar estos trastornos (Hiller and Thornton 2008).

Cambios bruscos de temperatura y en la cantidad de lluvia no pueden ser evitadas en las áreas de producción de Florida. Por lo tanto es necesario manejar apropiadamente el riego por subirrigación, el balance nutritivo y el espaciamiento de las semillas para reducir el estrés y la incidencia del centro marrón y el corazón hueco.

\section{Más Información}

Bohl, W. H., and S. B. Johnson, eds. 2010. “Commercial Potato Production in North America: The Potato Association of America Handbook." The Potato Association of America. http://potatoassociation.org/documents/A_ProductionHandbook_Final_000.pdf.

Zotarelli, L., P. D. Roberts, P. J. Dittmar, S. E. Webb, S. A. Smith, B. M. Santos, and S. M. Olson. 2012. Potato Production in Florida. HS733. Gainesville: University of Florida Institute of Food and Agricultural Sciences. http://edis.ifas. ufl.edu/cv131.

\section{Referencias}

Bussan, A. J. 2008. “The Canon of Potato Science: 45. Brown Centre and Hollow Heart." Potato Research 50(3-4) :395-398.

Christ, B. J. 1998. "Identifying Potato Diseases in Pennsylvania." Penn State College of Agricultural Sciences. Accessed January 11, 2012. http://pubs.cas.psu.edu/FreePubs/ pdfs/agrs75.pdf.

Hiller, L. K., D. C. Koller, and R. E. Thornton. 1985. "Physiological Disorders of Potatoes." In Potato Physiology, edited by P.H. Li, 389-455. New York: Academic Press.

Hiller, L.K., and R. E. Thornton. 2008. "Managing Physiological Disorders.” In Potato Health Management: Plant Health Management Series, edited by D. A. Johnson, 235-245. St. Paul, MN: The American Phytopathological Society. 
McCann, I. R., and J. C. Stark. 1989. "Irrigation and

Nitrogen Management Effects on Potato Brown Center and

Hollow Heart." HortScience 24(6): 950-952.

Rex, B. L., and G. Mazza. 1989. "Cause, Control and Detection of Hollow Heart in Potatoes: A Review." American Potato Journal 66(3): 165-183.

Selman, L., N. Andrews, A. Stone, and A. Mosley. 2008. "What's Wrong with My Potato Tubers? Diagnosing Tuber Abnormalities in Western Oregon and Washington." Oregon State University Extension Service and Western Region Sustainable Agriculture Research and Education. Accessed January 8, 2012. http://extension.oregonstate.edu/ catalog/pdf/em/em8948-e.pdf.

Van Denburgh, R. W., L. K. Hiller, and D. C. Koller. 1986.

"Ultrastructural Changes in Potato Tuber Pith Cells During Brown Center Development." Plant Physiology 81(1):167-170. 